\title{
The Value of BECCS in IAMs: a Review
}

\author{
Alexandre C. Köberle ${ }^{1}$
}

Published online: 2 December 2019

(C) The Author(s) 2019

\begin{abstract}
Purpose of Review Integrated assessment model (IAM) scenarios consistent with Paris Agreement targets involve large negative emission technologies (NETs), mostly bioenergy with carbon capture and storage (BECCS). Such reliance on BECCS implies IAMs assign it a high value. Past analyses on the value of BECCS in IAMs have not explicitly addressed the role of model structure and assumptions as value drivers. This paper examines the extent to which the value of BECCS in IAMs is enhanced by model structure constraints and assumptions.

Recent Findings Predominant use of high discount rates (3.5-5\%) means models opt for delayed-action strategies for emissions mitigation that lead to high levels of cumulative net-negative emissions, while lower discount rates lead to reduce reliance on NETs. Until recently in the literature, most models limited NET options to only BECCS and afforestation, but introduction of other CDR options can reduce BECCS deployment. Constraints on grid penetration of variable renewable energy (VRE) is a determining factor on the level of BECCS deployment across models, and more constrained grid penetration of VREs leads to more BECCS in electricity generation.

Summary This paper concludes BECCS derives significant value not only from the existing structure of IAMs but also from what is not represented in models and by predominant use of high discount rates. Omissions include NETs other than BECCS and deforestation, low-carbon innovation in end-use technologies, grid resilience to intermittent sources, and energy use in agriculture production. As IAMs increasingly endogenize such constraints, the value of BECCS in resulting scenarios is likely to be dampened.
\end{abstract}

Keywords BECCS $\cdot$ IAMs $\cdot$ Bioenergy $\cdot$ Integrated assessment models $\cdot$ Negative emissions $\cdot$ Carbon dioxide removal

\section{Introduction}

The Paris Agreement (PA) has set targets to limit temperature increases relative to pre-industrial era to well below $2{ }^{\circ} \mathrm{C}$ with an effort to keep it under $1.5^{\circ} \mathrm{C}$ [1]. In order to meet these targets, recent Intergovernmental Panel on Climate Change (IPCC) reports emphasize the widespread and deep changes required in the global energy, agriculture, and land use systems in the coming decades [2,3]. Most scenarios included in these assessments that keep warming to well below $2{ }^{\circ} \mathrm{C}$ involve large amounts of carbon dioxide removal (CDR) from

This article is part of the Topical Collection on Deep Decarbonization $B E C C S$

Alexandre C. Köberle

a.koberle@imperial.ac.uk

1 Grantham Institute, Imperial College London, Exhibition Road, London SW7 2AZ, UK the atmosphere in the second half of the century $[4,5]$. These scenarios are based mostly on modelled runs from integrated assessment models (IAMs) that include representations of the socioeconomic and biophysical systems governing greenhouse gas emissions and the resulting changes to the atmosphere [6]. Technologies delivering CDR are known as negative emission technologies (NETs) such as afforestation, enhanced weathering, and soil carbon management $[7 \bullet, 8 \bullet]$. Until recently, the only NETs available in integrated assessment models (IAMs) were afforestation and bioenergy with carbon capture and storage (BECCS) [9, 10]. Modelling groups are now beginning to include another CDR, namely direct air carbon capture and storage (DACCS) [11••].

As the main NET, BECCS has been the subject of several peer-reviewed articles describing what it is, its technoeconomic characterization, and its application in climate scenarios [5, 12-16]. A few articles have attempted to describe its value as a mitigation technology [17-19]. These articles have focused on the value of BECCS in mitigation scenarios in terms of its importance in enabling models to find 
solutions to stringent mitigation targets and to reduce overall system costs compared with scenarios where BECCS is not available. In general, the literature on the role of BECCS in IAM scenarios show deployment of bioenergy is robust across both model types and technoeconomic assumptions [20••], suggesting that BECCS is an economically and technically robust response to the challenge of global climate change mitigation. However, an expert elicitation revealed that IAM assumptions underpinning the feasibility of BECCS in resulting scenarios may be overly optimistic [21•]. Thus, on the one hand, IAMs point to BECCS as essential for the achievement of Paris Agreement targets. On the other, model input assumptions may be unrealistically favouring BECCS. In addition, there is limited recognition in the IAM literature of model structure as a driver of value for BECCS. One notable exception [22••] describes how model structure enables consistently high shares of BECCS in IAM scenario results, but is limited to features that are present in the models. However, it omitted how what is left out of the models enhances BECCS deployment and did not explicitly address the issue of value. This paper examines the extent to which the value of BECCS in IAMs is enhanced by what is and what is not represented in the models, the constraints imposed to BECCS and/or other technologies, or assumptions on nontechnical parameters such as intergenerational equity or governance of the BECCS chain.

\section{Context and Definitions}

\section{IAMs and BECCS}

Integrated assessment models (IAMs) represent human interactions with the natural systems through mathematical formulations based on insights from physics, chemistry, biology, economics, sociology, and transition theory [23, 24]. They are useful tools to project the evolution of human activity and its environmental impacts into the future by either optimizing or simulating the evolution of these systems subject to exogenous constraints and assumptions [6]. Constraints may reflect physical limits and may include caps on growth rates of a given technology's market share, installed capacity, and biophysical potential. On the other hand, they may reflect socioeconomic constraints such as degree of substitutability of capital and labour, price elasticity of demand for various commodities, or the rate of time preference (discount rate).

IAMs have been the main tools to assess climate change and to develop mitigation scenarios for climate action to avoid dangerous climate change [25-28]. Because the models differ as to their structure, objective function, assumptions, and constraints, different models reach different solutions for the same problem. For example, to meet Paris Agreement targets, IAMs project different pathways for the energy system, which deploy different types of technologies at different levels [20••, 27].

Nonetheless, models do agree on a few results. As assessed by recent IPCC reports [2, 3], there is general agreement across models that the rate of emissions reduction is steep in order to meet the well below $2{ }^{\circ} \mathrm{C}$ target. Moreover, most scenarios assessed rely on negative emissions, mainly from BECCS, in the second half of the century [5, 9, 25, 29]. However, this reliance on BECCS has been criticized on several fronts [10, 30 $, 31,32]$. Reliance on NETs is controversial and has received much criticism [10], especially that reliance on NETs constitutes a "moral hazard" in that they allow decision-makers to postpone mitigation efforts today by relying on negative emissions in the future to bring $\mathrm{CO}_{2}$ concentrations back to levels compatible with Paris Agreement targets [33-35]. It must be said there have been ample warning and caveats from modelling groups that BECCS should not be seen as a "get out of jail free card" but "should be viewed as part of a wider mitigation portfolio, and not as an alternative to deep cuts in emissions in the near term" $[9,33]$.

\section{BECCS: the Concept and Its History}

The concept of BECCS goes back at least to the late 1990s [36], developed over the 2000s [37-41], and came to prominence in the late 2010s [12, 25, 42, 43]. BECCS was first introduced in IAMs technology portfolio in the late 2000s $[41,44]$, and its inclusion is now widespread. Until recently, the only CDR options were BECCS and afforestation [10], and due to the limited potential for afforestation, BECCS became the de facto CDR option available to IAMs at a large scale. As we shall see, negative emissions are the main source of the value of BECCS within the framework of IAMs, along with the fact that it also functions as an energy source. However, model structure and assumptions help explain the ubiquitous presence of BECCS in IAM scenario results. The next section describes current thinking on the value of BECCS in IAMs as it is explicitly treated in the literature. The following section examines how BECCS value is also driven by model structural features.

\section{Current Thinking on Value of BECCS in IAMs}

The value of BECCS for IAMs has been linked to two effects of its inclusion as a mitigation option in modelled scenarios [17]:

i) its ability to make feasible scenarios of ambitious mitigation targets, and

ii) a lowering of the overall system cost in mitigation scenarios. 
Feasibility of deep mitigation scenarios is facilitated by BECCS via its ability to provide negative emissions [18], allowing for smoother transitions to low-carbon technologies aligned with transition constraints assumed in IAMs. Assumed constraints may include growth limits of novel technologies like solar power or electric vehicles, ability for early retirement of vintage capacity (asset stranding), or the degree of demand elasticity. Most scenarios that include BECCS tend to deploy it later in the period of analysis as a way to remove from the atmosphere carbon emitted earlier in the period as a result of a smoother transition or delayed action [20••].

On the other hand, the value of bioenergy in IAMs is also driven by its versatility since it can be used to produce bioelectricity, liquid biofuels, charcoal, hydrogen, or biomaterials, thus providing options for hard to decarbonize (HtD) sectors like freight transport, aviation, and industry [18]. This versatility of bioenergy allows deployment where it is most valuable to the energy system, in terms of its energy value, its carbon removal value, or both. That is, this versatility allows a model to allocate the primary biomass feedstock for the production of secondary energy carriers to replace those with the highest marginal cost, driving down the overall cost of the system $[18,20 \bullet$, 45]. By enabling decarbonization of $\mathrm{HtD}$ sectors, BECCS contributes to making very ambitious scenarios feasible.

IAMs usually implement climate policy via a carbontax or a cap on cumulative $\mathrm{CO}_{2}$ emissions (the so-called carbon budget) over the period of analysis. Across IAMs, the tougher the target, the higher the value of BECCS [18]. Delaying the onset of the emissions constraint in scenarios (late accession or delay scenarios) reduces the amount of emissions allowances, making for a tighter budget $[46,47]$. The value of BECCS rises significantly in such scenarios [48] due to the versatile deployment of negative emissions the technology provides, enabling $\mathrm{CO}_{2}$ concentration in the atmosphere to overshoot the target and then be clawed back by CDR.

Because bioenergy carriers vary in their energy and carbon content, this means models deploying BECCS face a trade-off between maximizing negative emissions and associated revenues and enabling a low-carbon transition in sectors with little or no other options [30•]. This can be thought of as choosing between maximizing the economic value (rents from negative emissions) and maximizing the energetic value (decarbonizing challenging sectors) of bioenergy carriers. Because of this flexibility, BECCS can play a significant role in a net-zero world by providing alternatives in sectors where currently none exists, especially in delayed-action scenarios [20••, 49]. However, the amount of BECCS deployed in IAMs is driven by other drivers of value, some a result of model structure, which have not been jointly or explicitly assessed before. This is the topic of the next section.

\section{Drivers of Value of BECCS in IAMs}

An important driver of value for both BECCS and NETs in general is the discount rate used in a modelled scenario. As explained before, BECCS and NETs in general are particularly useful in allowing for a slower phase out of unabated fossil fuel use, since they allow for long-term removal of $\mathrm{CO}_{2}$ emitted in the short term. However, this depends on how much the scenario values the future, represented by the choice of the discount rate. Emmerling et al. [50••] show that the current choices of relatively high discount rates $(3.5-5 \%)$ mean models opt for delayed-action strategies for emissions mitigation when NETs are included in the technology portfolio. Interestingly, the study found lower discount rates lead to less overshoot of the threshold $\mathrm{CO}_{2}$ concentration associated with Paris Agreement targets, and lower levels of cumulative netnegative emissions. In addition, lower discount rates lead to higher average annual investments in solar and wind technologies in both 2 and $1.5^{\circ} \mathrm{C}$ scenarios [50••]. This suggests that NETs, and more specifically BECCS, may be entering the solution space of IAMs for the "wrong" reasons (discounting) rather than the role they were originally included for (hedging uncertainties) [51]. Discounting the future has ethical implications which are not considered, including the "moral hazard" concern mentioned above, a reliance on NETs that may never materialize at scale and, even if they do, "managing an artificial carbon sink that is larger than the entire land sink today" [35].

The value of BECCS is a function not only of how BECCS itself is represented, but also of what is not represented in the model. Until recently in the literature, most models did not represent other CDR technologies, limiting CDR options available to only BECCS and afforestation [52]. However, introduction of other CDR technologies in the model portfolio may reduce the value of BECCS. For example, Realmonte et al. [11••] found when DACCS is introduced, BECCS deployment is reduced by $20-37 \%$ across scenarios limiting temperature increases to $2{ }^{\circ} \mathrm{C}$ and $1.5^{\circ} \mathrm{C}$ by the end of the century, with DAC more than compensating for this so that cumulative net-negative emissions actually grow even as BECCS deployment decreases. Emmerling et al. [50••] also found that inclusion of DACCS leads to lower deployment of BECCS. Creutzig et al. [53•] find DACCS outperform BECCS in several indicators except cost. Assumptions on potential deployment of CCS tend to be on the optimistic side and this also enhances BECCS potential. However, since it does not apply exclusively to BECCS, it is beyond the scope of the paper. Nonetheless, the deployment of carbo-ducts to transport the captured $\mathrm{CO}_{2}$ is likely to suffer from more scale, seasonality, and location constraints than fossil CCS [54].

Another important consideration is how a model represents technology innovation. Most climate mitigation scenarios in the literature assume continued energy service demand growth 
with limited increases in end-use efficiency [55] and exclusion of disruptive innovation [56]. The inclusion of novel lowcarbon technologies tends to reduce BECCS deployment in IAM solutions. For example, a low energy demand (LED) scenario that includes advanced end-use technologies with lower final energy demand enabled one IAM to meet both energy demand and a $1.5^{\circ} \mathrm{C}$ temperature target without relying on any CCS or CDR [57]. In another example, the inclusion in another IAM of advanced technologies in industry, freight, and aviation enabled the model to "achieve the rapid and deep decarbonization of the energy system" consistent with Paris Agreement targets while reducing reliance on NETs by up to $18 \%$ compared with a scenario with only conventional technologies [58]. Grid penetration of variable energy sources (VREs) like wind and solar is usually constrained in IAMs to ensure a stable modelled grid, but the assumptions governing these constraints may be overly pessimistic of what is technically possible. Daioglou et al. [22••] identify constraints on grid penetration of VREs as a determining factor on the level of BECCS deployment across models, and find those with more limiting constraints on VREs tend to deploy more BECCS in electricity generation. This implies that pessimistic assumptions regarding storage capacity deployment increases the value of BECCS for a given model, and vice versa. The same can be said about options that add value to curtailed energy from VREs such as power-to-X technologies [59]. Mathiesen et al. [60] report lower bioenergy requirement in a $100 \%$ renewable energy system that draws stability of supply from using "new sources of flexibility such as solid, gaseous, and liquid fuel storage, thermal storage and heat pumps and battery electric vehicles" rather than only ensuring electric grid stability. In summary, conservative assumptions on the evolution of end-use technologies and innovation in low-carbon solutions create conditions favouring IAM reliance on CDR in general, and BECCS in particular as the main CDR option available in IAMs. Although most models represent endogenous technological learning ${ }^{1}$, this is done via learning curves with simplifying assumptions that are subject to criticism [61]. In addition, other mechanisms driving cost reductions tend to be omitted, such as spillover effects that tend to increase penetration of non-biomass renewable sources when included.

In addition to technological innovation, the role of institutional and social innovations in scenarios must be considered [62]. IAMs are beginning to incorporate aspects of behaviour change into "alternative pathways". Van Vuuren et al. [63] found the combination of lifestyle change and more optimistic technological assumptions leads to a reduction (but not elimination) of the need for CDR in mitigation scenarios consistent

\footnotetext{
${ }^{1}$ The common Integrated Assessment Model (IAM) documentation. Available at https://www.iamcdocumentation.eu/index.php/IAMC_wiki. Accessed on 09 Oct 2019.
}

with Paris Agreement targets. Likewise, Bertram et al. [64] find targeted policies and lifestyle changes reduce dependence on NETs.

Daioglou et al. [22••] shows BECCS deployment is relatively independent of its levelized cost of energy ( $L C O E$ ) across models. The study found biomass feedstock prices are more important in determining BECCS competitiveness in IAMs than are specific technology costs like capex and O\&M costs. Thus, price formation of feedstocks is extremely important in determining BECCS competitiveness. However, it is unclear whether IAMs fully account for costs of agricultural production as there is no literature that I am aware of documenting how it may be implemented, the assumptions involved, parameter values, etc. ${ }^{2}$ Models may not include feedbacks between gridded land use and agricultural models and the technology-rich energy sector models that comprise IAMs, meaning higher diesel and nitrogen fertilizer demand in the land use models may not cause higher demand in energy models for diesel or ammonia (the latter an energy-intensive precursor to synthetic fertilizers). This means that IAMs may be underestimating energy demand in agricultural production, especially when there are high agricultural intensification and yield improvements, often characteristic of deep mitigation scenarios. Water use is not always fully represented, and the energy requirements of pumping for irrigation is often not a driver of energy demand in the agricultural sector. Not fully accounting for agricultural production costs leads to lower energy crop prices, which increases BECCS competitiveness.

On the other hand, IAMs assume a significant availability of agricultural and forestry residues (and municipal solid waste in some cases), and their share of bioenergy feedstock increases at the expense of bioenergy crops in scenarios with high GHG emission pricing [66]. Because residues have very low or (near) zero cost and imply no additional deforestation or agricultural emissions, their use as a feedstock is favoured. Hanssen et al. [66] report IAMs in a model intercomparison study rely on residues for an average $50 \%$ of bioenergy feedstock in 2050. However, there is high variability across models $(\sim 10-70 \%)$ with model differences arising mainly from model structure and definitions. They conclude values are "within literatureestimated residue availability, but outliers and sustainability concerns warrant further exploration" and uncertainties remain concerning residue supply potentials.

\footnotetext{
${ }^{2}$ One model has incorporated a module for linking agricultural and fertilizer production following [65], but it has not yet been included in any published results.
} 
This means that, on average, half of bioenergy feedstock in analyzed scenarios come from dedicated energy crops, potentially leading to food security concerns $[45,67]$ and to conflicts over land (land grabbing) [68-70]. Yield projections vary across IAMs, but are projected to increase (generally faster in mitigation scenarios than in baselines ${ }^{3}$ ) following current trends in the short term and diverging depending on the scenario [71]. Increasing agricultural yields reduces pressures for land conversion to agriculture (land sparring). However, in the real world, higher productivity may actually lead to higher land prices which incentivize area expansion to produce more goods [72] or in order to secure land tenure or ownership [69], reducing the potential of higher land productivity to cause an increase in abandoned agricultural areas by increasing opportunity costs of land sparing [73]. The fact that many models do not represent these dynamics implies possible overestimation of the availability of "abandoned land" on which bioenergy production is assumed to take place, sometimes exclusively, in several IAMs.

Finally, there are several social, political, and ethical challenges to BECCS deployment $[21 \bullet, 35,74,75]$. Several studies point to the lack of representation of governance aspects of BECCS in IAMs $[7,74,76,77]$. This reduces modelled transaction costs of the BECCS chain from field to carbon sink, effectively increasing its perceived competitiveness in the models. Gough et al. [74] explore six governance and policy challenges to BECCS deployment highlighting "the importance of a whole systems approach" to assess BECCS potential as an effective mitigation option at scale. A key issue is the carbon balance of BECCS technologies. The whole chainfrom the production of biomass feedstock to conversion to the desired energy carrier through to carbon capture, compression, storage, and sequestration - may cause more GHG emissions than it sequesters, thus leading to positive instead of negative emissions. The actual balance depends on the performance of each step in the chain (which varies by region) and on existence of transparent and effective monitoring and verification schemes $[30 \bullet, 32,53 \cdot$, 74]. Such an international framework for the governance, crediting, and monitoring of BECCS requires a high level of cooperation across regions [32], a transaction cost not necessarily represented in IAMs, and major restructuring of government fiscal policy to compensate negative emissions [51]. Last but not least, the adoption in 2015 of Agenda 2030 and the Sustainable Development Goals (SDGs) [78] means mitigating climate change must now happen in the context of other societal goals. This imposes sustainability constraints to which BECCS has many vulnerabilities, especially due to implications to land use change, food security, water use, and biodiversity $[3,53 \bullet, 67,71,79,80]$. As IAMs

\footnotetext{
${ }^{3}$ Although IAMs generally project yields to grow in the short term, some scenarios may include pessimistic technological change leading to long-term declines, with SSP4 a case in point [71].
}

increasingly endogenize such constraints, the value of BECCS in resulting scenarios is likely to be dampened.

\section{Considerations on the Value of BECCS in IAMs}

The IPCC Special Report on $1.5^{\circ} \mathrm{C}[3]$ concluded that emissions in 2030 would have to be about half of 2010 levels to maintain a chance of meeting the well below $2{ }^{\circ} \mathrm{C}$ target of the Paris Agreement. If one accepts the adage that innovative technologies in the energy sectors take decades to go from prototype to scale [81], the transition leading to such steep reductions would have to be based on technologies existing today. The difficulty of meeting the 2030 milestone means overshot scenarios may be the only recourse we have to meet the $1.5^{\circ} \mathrm{C}$ target by 2100 , which forms the rationale behind the dominance of BECCS in IAM scenarios.

This article reviews the existing literature in a comprehensive manner to identify major drivers of value for BECCS in IAMs and shows it is enhanced not only by the assumptions and constraints imposed on BECCS and competing technologies, but also by what is and what is not represented in the models, that is, model structure.

To begin with, model structure and assumptions increase reliance on NETs which, in the current configuration of IAMs, effectively means reliance on BECCS since it is the only scalable NET modelled, the other being afforestation which has limited potential.

The literature suggests reliance on NETs stems from the dwindling carbon budget and a lack of effort to reduce emissions, meaning we will overshoot our temperature targets and need CDR to bring it back to Paris-consistent levels. However, NET deployment is enhanced by the choice of high discount rates (in the range of 3.5-5\%) in current scenario implementations. Higher discount rates imply the future is valued much less than the present, leading to lower effort in the short term than if lower discount rates were used. This brings up ethical issues of intergenerational justice harking back to the controversy following publication of the Stern Review [82-85]. Since there is no right or wrong answer here, this should be treated explicitly when scenarios are used to inform policy. This would confront decision-makers with the choice to favour the present by discounting the future more heavily, but this is not possible given the lack of scenarios with low(er) discount rates in the literature and, consequently, in IPCC assessments. Scenarios with lower discount rates place more emphasis on short-term deployment of low-carbon technologies like solar and wind, leading to narratives that deemphasize the reliance on NETs in general and BECCS in particular. On the other hand, the insufficient effort for emissions reduction in recent years may well be an indication that society does in fact have an implicit high discount rate, which means IAMs reflect that reality. Nonetheless, the role of the 
discount rate on the value of BECCS in IAMs should not be underestimated.

The versatility of bioenergy and its ability to combine with CCS to provide negative emissions drive the value of BECCS by making ambitious scenarios feasible and reducing mitigation costs, and this has been established in the literature for some time. However, the value of BECCS in IAMs also stems from it being the only NET modelled besides afforestation. Adding other NETs like DACCS to model portfolios reduces the value of BECCS, despite the fact that BECCS outcompetes DACCS on cost [53•]. This cost advantage may also be exacerbated in models by the availability of low-cost, low-impact residues as input for BECCS. Analogously, competitiveness of DACCS is improved when waste heat is made available to it as an energy input [11••] so it is important to include this as an option when implementing DACCS in IAMs. Including residue for BECCS but not waste heat for DACCS may be favouring BECCS.

Additionally, state-of-the art IAMs include novel technologies conservatively, so that the suite of options available in 2100 is not very different from what is deemed possible today. IAMs generally do not include disruptive innovation and technologies which may be game changers that may render unrecognizable the sectors they impact $[51,56]$. Policy frameworks consistent with lower discount rates must reach beyond just the required technological innovation and embrace more challenging forms of innovation such as institutional innovation or less "palatable" ones like behaviour or lifestyle change [62]. Institutional innovation includes global cooperation in a concerted climate action effort that avoids any more delay. Behaviour change includes diet change to less meat intensive diets, or avoidance of carbon-intensive modes of transportation (e.g. single-occupant cars). IAMs are beginning to incorporate some of these changes to the extent possible as seen for example in Grubler et al. [57], Bertram et al. [64] and van Vuuren et al. [63], leading to less reliance on NETs and BECCS. Thus, a lower propensity for social and institutional innovations may drive up the need for CDR and increase the value of NETs. To the extent that this is reflective of reality, it can be said that the value of NETs is real in our efforts to curb climate change. Nonetheless, as the main NET available in IAMs until recently, BECCS is given more value than it is perhaps due.

This paper argues that the value of BECCS in IAMs is a result of not only what is represented in the models but also what is not, and that model structure is hence an important driver of value for BECCS. This can also be generalized to all NETs, and with increasing implementation of other NETs in IAMs, BECCS will tend to lose ground to them in the results of modelled scenarios. In addition, as IAMs increasingly include endogenous representation of the SDGs, the trade-offs from bioenergy production and use across many of the goals and targets will place constraints on BECCS deployment. In summary, as IAMs evolve to better address the issues raised here, the less reliance on BECCS we are likely to see, although it will likely not disappear from scenarios altogether. In the end, BECCS does have a role to play in a low-carbon future in sectors and activities for which it is best suited: hard to decarbonize sectors and to the extent its social, economic, and environmental sustainability can be assured.

\section{Conclusions}

- Value of BECCS in IAMs in the literature linked to versatility of bioenergy and ability to provide negative emissions by combining with carbon capture and storage (CCS). Both characteristics of bioenergy contribute to enabling BECCS to (i) make feasible scenarios with ambitious mitigation targets, and (ii) lower overall cost of mitigation (same mitigation for lower carbon price).

- The discount rate assumed in models has profound impacts on deployment of BECCS and of NETs in general. Higher discount rates favour delayed mitigation in IAMs, meaning short-term emissions decrease more slowly and must be compensated for by CDR in the long term.

- Recent literature suggests the value of BECCS to IAMs is driven by model structure, including what is not represented by the models. The (un)availability of novel lowcarbon technologies, demand side reductions, and behaviour change increases reliance on CDR, mainly through BECCS. In addition, constraints on grid penetration limits to VREs impose limits to their deployment shifting more value to BECCS. Conservative assumptions on innovation potential in general drive up the value of BECCS for IAMs, whether one means technological (batteries, hydrogen, power-to-X), institutional (finance, R\&D, global cooperation, demand response), or social (behaviour change) innovation.

- Until recently, limited CDR options in IAMs included only BECCS and afforestation as the only NETs and, since afforestation potential is limited, BECCS accounted for the lion's share of negative emissions. With inclusion of other NETs in IAM portfolios, a share of the value of BECCS will be claimed by other options.

- Lack of representation of governance and sustainability concerns - such as monitoring and verifying the carbon balance of the BECCS chain or managing impacts on food prices - may reduce transaction costs of BECCS in the models.

- $\quad$ BECCS does have a role to play in a low-carbon future especially in hard to decarbonize sectors - and its early stage deployment should be supported to enable the technology to reach its potential while keeping within sustainability constraints. 


\section{Compliance with Ethical Standards}

Conflict of Interest The author declares that he has no conflict of interest.

Human and Animal Rights and Informed Consent This article does not contain any studies with human or animal subjects performed by any of the authors

Open Access This article is distributed under the terms of the Creative Commons Attribution 4.0 International License (http:// creativecommons.org/licenses/by/4.0/), which permits unrestricted use, distribution, and reproduction in any medium, provided you give appropriate credit to the original author(s) and the source, provide a link to the Creative Commons license, and indicate if changes were made.

\section{References}

Papers of particular interest, published recently, have been highlighted as:

- Of importance

•- Of major importance

1. UNFCCC. Paris Agreement. Conference of the Parties on its twenty-first session Paris, France: UN Framework Convention on Climate Change (UNFCCC); 2015 p. 32.

2. IPCC. Summary for Policy Makers. In: Stocker TF, Qin D, Plattner G-K, Tignor M, Allen SK, Boschung J, et al., editors. Climate change 2013: the physical science basis Contribution of Working Group I to the Fifth Assessment Report of the Intergovernmental Panel on Climate Change. Geneva: Intergovernmental Panel on Climate Change (IPCC); 2013. p. 1535.

3. IPCC. Summary for Policymakers. In: Masson-Delmotte V, Zhai P, Pörtner HO, Roberts D, Skea J, Shukla PR, et al., editors. Global warming of $15^{\circ} \mathrm{C} \mathrm{An} \mathrm{IPCC} \mathrm{special} \mathrm{report} \mathrm{on} \mathrm{the} \mathrm{impacts} \mathrm{of} \mathrm{global}$ warming of $15{ }^{\circ} \mathrm{C}$ above pre-industrial levels and related global greenhouse gas emission pathways, in the context of strengthening the global response to the threat of climate change. Geneva: World Meteorological Organization; 2018. p. 32.

4. Rogelj J, Shindell D, Jiang K, Al E. Mitigation pathways compatible with $1.5{ }^{\circ} \mathrm{C}$ in the context of sustainable development. In: Masson-Delmotte V, Zhai P, Pörtner HO, Roberts D, Skea J, Shukla PR, et al., editors. Global warming of $15{ }^{\circ} \mathrm{C}$ An IPCC special report on the impacts of global warming of $15^{\circ} \mathrm{C}$ above pre-industrial levels and related global greenhouse gas emission pathways, in the context of strengthening the global response to the threat of climate change. Geneva: Intergovernmental Panel on Climate Change (IPCC); 2018.

5. Kriegler E, Luderer G, Bauer N, Baumstark L, Fujimori S, Popp A, et al. Pathways limiting warming to $1.5^{\circ} \mathrm{C}$ : a tale of turning around in no time? Philos Trans Ser A Math Phys Eng Sci. 2018;376: 20160457.

6. Weyant J. Some contributions of integrated assessment models of global climate change. Rev Environ Econ Policy. 2017;11:115-37.

7. Fuss S, Lamb WF, Callaghan MW, Hilaire J, Creutzig F, Amann T, et al. Negative emissions - part 2: costs, potentials and side effects. Environ Res Lett. 2018;13:063002 An excellent review of costs, potentials, and side effects of NETs, including BECCS.
8. Minx JC, Lamb WF, Callaghan MW, Fuss S, Hilaire J, Creutzig F, et al. Negative emissions - part 1: research landscape and synthesis. Environ Res Lett. 2018;13:063001 Comprehensive literature review focusing on seven technologies: BECCs, afforestation and reforestation, DACCS, enhanced weathering, ocean fertilisation, biochar, and soil carbon sequestration.

9. Fuss S, Lamb WF, Max W, Minx JC, Lamb WF, Max W, et al. Research priorities for negative emissions. Environ Res Lett. 2016;11:11.

10. Gambhir A, Butnar I, Li P-H, Smith P, Strachan N, Gambhir A, et al. A review of criticisms of integrated assessment models and proposed approaches to address these, through the lens of BECCS. Energies. Multidisciplinary Digital Publishing Institute. 2019;12: 1747.

11.• Realmonte G, Drouet L, Gambhir A, Glynn J, Hawkes A, Köberle $\mathrm{AC}$, et al. An inter-model assessment of the role of direct air capture in deep mitigation pathways. Nat Commun. 2019;10:3277 The first multi-model IAM comparison exercise including DACCS and providing an in-depth assessment of its deployment and impacts on other technologies, especially BECCS.

12. Kemper J. International Journal of Greenhouse Gas Control Biomass and carbon dioxide capture and storage: a review. Int J Greenhouse Gas Contrl. 2015;40:401-30.

13. Krause A, Pugh TAM, Bayer AD, Li W, Leung F, Bondeau A, et al. Large uncertainty in carbon uptake potential of land-based climatechange mitigation efforts. Glob Chang Biol. 2018;24:3025-38.

14. Field CB, Mach KJ. Rightsizing carbon dioxide removal. Science. 2017;356:706-7.

15. Smolker R. Bioenergy with carbon capture and sequestration (BECCS): the distracting injustice of an infeasible and unlikely Technofix. Development [Internet]. 2019; [cited 2019 Oct 9]; Available from: http://link.springer.com/10.1057/s41301-01900213-4.

16. Muri $\mathrm{H}$. The role of large - scale BECCS in the pursuit of the $1.5^{\circ} \mathrm{C}$ target: an Earth system model perspective. Environ Res Lett. 2018;13:044010.

17. Kraxner F, Fuss S, Krey V, Best D, Kindermann G, Yamagata Y, et al. The role of bioenergy with carbon capture and storage (BECCS) for climate policy. Handbook of Clean Energy Systems: Wiley; 2015. https://doi.org/10.1002/9781118991978.hces049.

18. Klein D, Luderer G, Kriegler E, Strefler J, Bauer N, Leimbach M, et al. The value of bioenergy in low stabilization scenarios: an assessment using REMIND-MAgPIE. Clim Chang. 2014;123: 705-18.

19. Azar C, Johansson DJA, Mattsson N. Meeting global temperature targets - the role of bioenergy with carbon capture and storage. Environ Res Lett. 2013;8:034004. https://doi.org/10.1088/17489326/8/3/034004.

20.• Bauer N, Rose SK, Fujimori S, Van Vuuren D, Weyant J, Wise M, et al. Global energy sector emission reductions and bioenergy use: overview of the bioenergy demand phase of the EMF-33 model comparison. Clim Chang. 2018; An in-depth overview of a multi-IAM comparison project (EMF33) focusing on bioenergy deployment. It provides excellent overview of how models represent and deploy BECCS and the versatility of bioenergy through its deployment in both electricity and liquid fuel production.

21. Vaughan NE, Gough C. Expert assessment concludes negative emissions scenarios may not deliver. Environ Res Lett. 2016;11: 095003. https://doi.org/10.1088/1748-9326/11/9/095003 Expert elicitation concluding assumptions about BECCS in IAMs may not reflect reality.

22.• Daioglou V, Rose S, Bauer N, Kitous A, Muratori M, Sano F, et al. Bioenergy technologies in long-run climate change mitigation: results from the EMF33 study. Clim Chang. submitted; An excellent 
assessment of bioenergy technologies including BECCS and impacts of model structure on its deployment.

23. Krey V. Global energy-climate scenarios and models: a review. WIREs Energy Environ. 2014;3:363-83.

24. Krey V, Guo F, Kolp P, Zhou W, Schaeffer R, Awasthy A, et al. Looking under the hood: a comparison of techno-economic assumptions across national and global integrated assessment models. Energy. 2019;172:1254-67.

25. Clarke LE, Jiang K, Akimoto K, Babiker M, Blanford G, FisherVanden K, et al. Assessing transformation pathways. In: Edenhofer O, Pichs-Madruga R, Sokona Y, Farahani E, Kadner S, Seyboth K, et al., editors. Climate change 2014: mitigation of climate change Contribution of Working Group III to the Fifth Assessment Report of the Intergovernmental Panel on Climate Change. Cambridge: Cambridge University Press; 2014. p. 413-510.

26. Nakićenović N, Victor N, Morita T. Emissions scenarios database and review of scenarios. Mitig Adapt Strateg Glob Chang. 1998;3: 95-131.

27. Riahi K, van Vuuren DP, Kriegler E, Edmonds J, O’Neill BC, Fujimori S, et al. The shared socioeconomic pathways and their energy, land use, and greenhouse gas emissions implications: an overview. Glob Environ Chang. 2017;42:153-68.

28. Vuuren DP, Edmonds JA, Kainuma M, Riahi K, Weyant J. A special issue on the RCPs. Clim Chang. 2011;109:1-4.

29. Rogelj J, Popp A, Calvin KV, Luderer G, Emmerling J, Gernaat D, et al. Scenarios towards limiting global mean temperature increase below $1.5^{\circ} \mathrm{C}$. Nat Clim Chang. Springer US. 2018;8:325-32.

30. Fajardy M, Köberle AC, Mac Dowell N, Fantuzzi A. BECCS deployment: a reality check. London; 2019. Report No.: 28. Available from http://www.imperial.ac.uk/grantham/publications/briefingpapers/. A recent briefing paper on BECCS deployment and constraints done in non-academic language. Useful for decision-makers.

31. Creutzig F, Ravindranath NH, Berndes G, Bolwig S, Bright R, Cherubini $\mathrm{F}$, et al. Bioenergy and climate change mitigation: an assessment. GCB Bioenergy. 2015;7:916-44.

32. Peters GP, Geden O. Catalysing a political shift from low to negative carbon. Nat Clim Chang. Nature Publishing Group. 2017;7: 619-21.

33. Fuss S, Canadell JG, Peters GP, Tavoni M, Andrew RM, Ciais P, et al. Betting on negative emissions. Nat Clim Chang. Nature Publishing Group, a division of Macmillan Publishers Limited All Rights Reserved. 2014;4:850.

34. Larkin A, Kuriakose J, Sharmina M, Anderson K. What if negative emission technologies fail at scale? Implications of the Paris Agreement for big emitting nations. Clim Pol. 2018;18:690-714.

35. Lenzi D, Lamb WF, Hilaire J. Weigh the ethics of plans to mop up carbon dioxide. Nature. 2018;561:303-5.

36. Williams RH. Lifecycle $\mathrm{CO} 2$ emissions - without and with $\mathrm{CO} 2$ sequestration. In: Ayres RU, Weaver PM, editors. Ecorestructuring: implications for sustainable development. New York: United Nations University Press; 1998. p. 423.

37. Keith DW. Sinks, energy crops and land use: coherent climate policy demands an integrated analysis of biomass. Clim Chang. 2001;49:1-10.

38. Kraxner F, Nilsson S, Obersteiner M. Negative emissions from BioEnergy use, carbon capture and sequestration (BECS) - the case of biomass production by sustainable forest management from semi-natural temperate forests. Biomass Bioenergy. 2003;24:28596.

39. Obersteiner M, Azar C, Kauppi P, Möllersten K, Moreira J, Nilsson S, et al. Managing climate risk. Science. 2001;294:786 LP - 787.

40. Mollersten K, Yan J, Moreira JR. Potential market niches for biomass energy with CO 2 capture and storage - opportunities for energy supply with negative CO 2 emissions. Biomass Bioenergy. $2003 ; 25: 273-85$.
41. van Vuuren DP, den Elzen MGJ, Lucas PL, Eickhout B, Strengers $\mathrm{BJ}$, van Ruijven B, et al. Stabilizing greenhouse gas concentrations at low levels: an assessment of reduction strategies and costs. Clim Chang. 2007;81:119-59.

42. Tavoni M, Socolow R. Modeling meets science and technology: an introduction to a special issue on negative emissions. Clim Chang. 2013;118:1-14.

43. Blanford GJ, Kriegler E, Tavoni M. Harmonization vs. fragmentation: overview of climate policy scenarios in EMF27. Clim Chang. 2014;123:383-96.

44. Kemper J. International Journal of Greenhouse Gas Control Biomass and carbon dioxide capture and storage: a review. Int $\mathrm{J}$ Greenhouse Gas Contrl. 2015;40:401-30.

45. Muratori M, Calvin K, Wise M, Kyle P, Edmonds J. Global economic consequences of deploying bioenergy with carbon capture and storage (BECCS). Environ Res Lett. IOP Publishing. 2016;11: 095004.

46. Millar R, Fuglestvedt J, Friedlingstein P, et al. Emission budgets and pathways consistent with limiting warming to $1.5^{\circ} \mathrm{C}$. Nat Geosci. 2017;10:741-7. https://doi.org/10.1038/ngeo3031.

47. Rogelj J, Schaeffer M, Friedlingstein P, Gillett NP, Van Vuuren DP, Riahi K, et al. Differences between carbon budget estimates unravelled. Nat Clim Chang. Nature Publishing Group. 2016;6: 245-52.

48. Edmonds J, Luckow P, Calvin K, Wise M, Dooley J, Kyle P, et al. Can radiative forcing be limited to $2.6 \mathrm{Wm}-2$ without negative emissions from bioenergy AND CO2 capture and storage? Clim Chang. 2013;118:29-43.

49. Mintenig J, Khabbazan MM, Held $\mathrm{H}$. The role of bioenergy and carbon capture and storage (BECCS) in the case of delayed climate policy - insights from cost-risk analysis. Earth Syst Dynam Discuss. 2017:1-30. https://doi.org/10.5194/esd-2017-117.

50.• Emmerling J, Drouet L, van der Wijst K-I, Van Vuuren D, Bosetti $\mathrm{V}$, Tavoni M. The role of the discount rate for emission pathways and negative emissions. Environ Res Lett [Internet]. 2019; [cited 2019 Aug 27]; Available from: http://iopscience.iop.org/article/10. 1088/1748-9326/ab3cc9. An excellent research paper showing how results are driven by the choice of discount rates. Sensitivities show deployment of NETs and BECCS to decline with choice of lower discount rates.

51. Bednar J, Obersteiner M, Wagner F. On the financial viability of negative emissions. Nat Commun. 2019;10:8-11.

52. Smith P, Bustamante M, Ahammad H, Clark H, Dong H, Elsiddig EA, et al. Agriculture, forestry and other land use. In: Edenhofer O, Pichs-Madruga R, Sokona Y, Farahani E, Kadner S, Seyboth K, et al., editors. Climate change 2014: mitigation of climate change Contribution of Working Group III to the Fift Assessment Report of the Intergovernmental Panel on Climate Change [Internet]. Cambridge: Cambridge University Press; 2014. p. 811-922. Available from: https://www.ipcc.ch/report/ar5/wg3/.

53. Creutzig F, Breyer C, Hilaire J, Minx J, Peters GP, Socolow R. The mutual dependence of negative emission technologies and energy systems. Energy Environ Sci. 2019;12:1805-17 Assessment of NETs and comparison between DACCS and BECCS on several parameters.

54. Gough C, Upham P. Biomass energy with carbon capture and storage (BECCS): a review [Internet]. Tyndall Center for Climate Change Research; 2010. Report No.: Working Paper 147. Available from: http://citeseerx.ist.psu.edu/viewdoc/download? doi=10.1.1.231.3339\&rep=rep1\&type $=$ pdf

55. Wilson C, Grubler A, Gallagher KS, Nemet GF. Marginalization of end-use technologies in energy innovation for climate protection. Nat Clim Chang. 2012;2:780-8.

56. Wilson C, Pettifor H, Cassar E, Kerr L, Wilson M. The potential contribution of disruptive low-carbon innovations to $1.5^{\circ} \mathrm{C}$ climate mitigation. Energy Efficienc. 2019;12:423-40. 
57. Grubler A, Wilson C, Bento N, Boza-Kiss B, Krey V, McCollum $\mathrm{DL}$, et al. A low energy demand scenario for meeting the $1.5^{\circ} \mathrm{C}$ target and sustainable development goals without negative emission technologies. Nat Energy. Springer US. 2018;3:515-27.

58. Napp TA, Few S, Sood A, Bernie D, Hawkes A, Gambhir A. The role of advanced demand-sector technologies and energy demand reduction in achieving ambitious carbon budgets. Appl Energy. 2019;238:351-67.

59. Vázquez FV, Koponen J, Ruuskanen V, Bajamundi C, Kosonen A, Simell P, et al. Power-to-X technology using renewable electricity and carbon dioxide from ambient air: SOLETAIR proof-of-concept and improved process concept. J CO2 Util. 2018;28:235-46.

60. Mathiesen BV, Lund H, Connolly D, Wenzel H, Østergaard PA, Möller B, et al. Smart Energy Systems for coherent 100\% renewable energy and transport solutions. Appl Energy. 2015;145:13954.

61. Witajewski-Baltvilks J, Verdolini E, Tavoni M. Bending the learning curve. Energy Econ. 2015;52:S86-99.

62. Kramer GJ. Energy scenarios - exploring disruption and innovation. Energy Res Soc Sci. 2018;37:247-50.

63. van Vuuren DP, Stehfest E, Gernaat DEHJ, van den Berg M, Bijl $\mathrm{DL}$, de Boer HS, et al. Alternative pathways to the $1.5^{\circ} \mathrm{C}$ target reduce the need for negative emission technologies. Nat Clim Chang. 2018;8:391-7.

64. Bertram C, Luderer G, Popp A, Minx JC, Lamb William F, Stevanović M, et al. Targeted policies can compensate most of the increased sustainability risks in $1.5{ }^{\circ} \mathrm{C}$ mitigation scenarios. Environ Res Lett. 2018;13:64038.

65. Nortier N. Modeling agricultural energy demand within the IMAGE 3.0 framework [Internet] [Master's]. [Utrecht, The Netherlands]: Utrecht University; 2016 [cited 2019 Aug 22]. Available from: https://dspace.library.uu.nl/handle/1874/341406

66. Hanssen SV, Daioglou V, Steinmann ZJN, Frank S, Popp A, Brunelle $\mathrm{T}$, et al. Biomass residues as 21 st century bioenergy feedstock - a comparison of eight integrated assessment models. Climat Change [Internet]. 2019. https://doi.org/10.1007/s10584-01902539-x.

67. Hasegawa T, Fujimori S, Havlík P, Valin H, Bodirsky BL, Doelman $\mathrm{JC}$, et al. Risk of increased food insecurity under stringent global climate change mitigation policy. Nat Clim Chang. Springer US. 2018;8:699-703

68. Borras SM, Fig D, Suárez SM. The politics of agrofuels and megaland and water deals: insights from the ProCana case, Mozambique. Rev Afr Polit Econ. 2011;38:215-34.

69. Romeu-Dalmau C, Gasparatos A, von Maltitz G, Graham A, Almagro-Garcia J, Wilebore B, et al. Impacts of land use change due to biofuel crops on climate regulation services: five case studies in Malawi, Mozambique and Swaziland. Biomass and Bioenergy. 2018;114:30-40. https://doi.org/10.1016/j.biombioe.2016.05.011.
70. von Maltitz G, Setzkorn K. Potential impacts of biofuels on deforestation in Southern Africa. J Sustain For. 2012;31:80-97.

71. Popp A, Calvin K, Fujimori S, Havlik P, Humpenöder F, Stehfest E, et al. Land-use futures in the shared socio-economic pathways. Glob Environ Chang. Elsevier Ltd. 2017;42:331-45.

72. Rose SKR, Glub AA, Sohngen B. Total factor and relative agricultural productivity and deforestation. Am J Agric Econ. 2013;95: 426-34.

73. Nepstad D, Soares-filho BS, Merry F, Lima A, Moutinho P, Carter $\mathrm{J}$, et al. The end of deforestation in the Brazilian Amazon. Science. 2009;326:1350-1.

74. Gough C, Garcia-Freites S, Jones C, Mander S, Moore B, Pereira C, et al. Challenges to the use of BECCS as a keystone technology in pursuit of 1.50C. Glob Sustain. 2018;1:e5.

75. Geden O, Scott V, Palmer J. Integrating carbon dioxide removal into EU climate policy: prospects for a paradigm shift. WIREs Clim Change. 2018;9:e521.

76. Anderson K, Peters G. The trouble with negative emissions. Science. 2016;354:182-3.

77. Torvanger A. Governance of bioenergy with carbon capture and storage (BECCS): accounting, rewarding, and the Paris agreement. Clim Policy. Taylor \& Francis. 2019;19:329-41.

78. United Nations. Transforming our world: the 2030 Agenda for Sustainable Development. 2015 p. 1-35.

79. Stechow CV, Jakob M, Steckel JC, Rogelj J, Reisinger A, Mccollum DL, et al. $2{ }^{\circ} \mathrm{C}$ and SDGs: united they stand, divided they fall? Environ Res Lett. IOP Publishing. 2016;11:34022.

80. Nilsson M, Chisholm E, Griggs D, Howden-Chapman P, McCollum D, Messerli P, et al. Mapping interactions between the sustainable development goals: lessons learned and ways forward. Sustain Sci. Springer Japan. 2018;13:1489-503.

81. Wilson C. Up-scaling, formative phases, and learning in the historical diffusion of energy technologies. Energy Policy. Elsevier. 2012;50:81-94.

82. Stern N. The economics of climate change: the stern review [Internet]. Cambridge: Cambridge University Press; 2007. Available from: https://www.cambridge.org/core/books/economicsof-climate-change/A1E0BBF2F0ED8E2E4142A9C878052204

83. Nordhaus WD. A review of the stern review on the economics of climate change. J Econ Lit. 2007;45:686-702.

84. Nordhaus W. ECONOMICS: critical assumptions in the stern review on climate change. Science. 2007;317:201-2.

85. Weitzman ML. A review of the stern review on the economics of climate change. J Econ Lit. 2007;45:703-24.

Publisher's Note Springer Nature remains neutral with regard to jurisdictional claims in published maps and institutional affiliations. 